\title{
A Novel Method of Identifying the Internal Acoustic Canal in the Middle Fossa Approach in a Cadaveric Study-The Rule of 2s
}

\author{
Raghuram Sampath ${ }^{1}$ Chad Glenn ${ }^{1}$ Shashikant Patil ${ }^{1}$ Prasad Vannemreddy ${ }^{1}$ Lawrence Gardner ${ }^{2}$ \\ Anil Nanda ${ }^{1}$ Bharat Guthikonda ${ }^{1}$ \\ ${ }^{1}$ Department of Neurosurgery, Louisiana State University Health \\ Sciences Center, Shreveport, Louisiana, United States \\ 2 Department of Neuro-Otology, Louisiana State University Health \\ Sciences Center, Shreveport, Louisiana, United States

\begin{abstract}
Address for correspondence and reprint requests Bharat Guthikonda, M.D., Department of Neurosurgery; Director of Skull Base Research, Louisiana State University Health Sciences Center, 1501 Kings Highway, Shreveport, LA 71130, United States
\end{abstract} \\ (e-mail: bguthi@Isuhsc.edu).
}

J Neurol Surg B 2012;73:253-260.

\begin{abstract}
Keywords

- petrous apex

- foramen ovale

- foramen spinosum

- internal acoustic canal

- middle fossa

Objective Multiple landmarks and anatomic relationships exist to identify internal acoustic canal (IAC) in middle fossa approach for removing intracanalicular schwannomas. We attempted to identify a reproducible, practical method to quickly identify the IAC that would be applicable when an expanded middle fossa approach is required.

Design Middle fossa approach was performed on 10 cadavers (21 dissections). In the first head, temporal and suboccipital craniotomies were performed to identify landmarks and formulate a hypothesis. Porous acusticus (PA) was identified and IAC was circumferentially skeletonized into middle fossa. Orientation of IAC in the middle fossa was evaluated in relation to foramen spinosum (FS), foramen ovale (FO), petrous ridge, and petrous apex. Consistency of this relationship was tested in the remaining heads. Results The opening of PA (point A) was consistently found at a mean of $2.38 \mathrm{~cm}$ posterolateral to the petrous apex along the petrous ridge (range 2.1 to 2.8). A line was drawn from the FO to FS and extrapolated posteriorly. The IAC (point B) was found a mean distance of $2.39 \mathrm{~cm}$ from FS along the FS-FO line (range 2.1 to 2.8). The course of IAC was consistently found by connecting point $A$ to point $B$.

Conclusion A novel, practical, and reproducible method is described to identify the IAC via the expanded middle fossa approach.
\end{abstract}

\section{Introduction}

Identifying the internal acoustic canal (IAC) via the expanded middle fossa approach is surgically useful for operating on a variety of pathology, including large petroclival meningiomas, large trigeminal/vestibular schwannomas, and lateral clival chondrosarcomas, amongst others. The approaches to the IAC used previously have been the middle cranial fossa approach $^{1-13}$ and retrosigmoid and translabyrinthine approach. Approaching through the middle fossa helps to preserve hearing; thus it has been used by otolaryngologists

received

August 14, 2011

accepted after revision

January 13, 2012

published online

May 17, 2012 and neurosurgeons alike. Various methods of identifying the porous acusticus (PA) and various landmarks have been described previously to delineate the orientation of the IAC. While hearing is at risk with translabyrinthine approaches, with the retrosigmoid approach a smaller operative area is available in addition to more structures being encountered along with the inability to visualize the lateral extent of the IAC. $^{14}$ The middle cranial fossa approach circumvents both these difficulties. In addition up till the tympanic part, all the preceding parts of the facial nerve can be visualized with this approach. The middle fossa approach has seen modifications
Copyright ( 2012 by Thieme Medical Publishers, Inc., 333 Seventh Avenue, New York, NY 10001, USA. Tel: +1(212) 584-4662.
DOI http://dx.doi.org/ 10.1055/s-0032-1312711. ISSN 2193-6331. 
over the years such as the extended middle fossa approach involving a larger opening of the petrous pyramid. ${ }^{1,13,15,16}$ The landmarks, measurements, and angles described in other studies are to an extent cumbersome and technically difficult to identify the IAC intraoperatively but nonetheless have been employed in many clinical series. We performed cadaveric dissections to this end to identify constant bony landmarks and describe methods of locating the PA and IAC that are, easy to understand and reproduce, reliable and could potentially employed with relative ease intraoperatively during an expanded middle fossa approach.

\section{Methods}

A total of 21 adult cadaveric sides were dissected in all. In the first head, experimental dissection was performed to identify landmarks and their orientations, formulate a hypothesis, and record some distances between various structures. A middle fossa approach was employed, and the craniotomy was performed two-third anterior to and one-third posterior to the external acoustic canal (EAC). As the first head was used more for experimentation, we also performed a suboccipital craniotomy to perceive the orientation of landmarks from a posterior view, and we then formed a composite image of all the landmarks. We used the following bony landmarks: the petrous apex, the foramen spinosum (FS) and foramen ovale (FO), the foramen lacerum and petrous ridge in the middle fossa, and the jugular foramen and PA posteriorly. One complete skull bone was also studied. From the initial experimental head, the relationship of FO and FS, and the distance of the PA from the petrous apex were noted. Also, once the PA and the auditory-facial fasciculus were identified from the posterior approach, we drilled open the IAC while tracing these nerves as they entered the petrous temporal bone using high-speed drills. Once the IAC was completely drilled from the posterior approach, the anatomy of the skeletonized IAC and its relation to structures in the middle cranial fossa was studied. This helped us in forming a hypothesis to test in the remaining cadaveric heads.

In the remaining heads, we used a middle fossa approach and went in a subtemporal plane, retracting the temporal lobe as we separated the dura off the middle fossa floor dissecting in this plane toward the petrous apex. The FO, FS, foramen lacerum, and petrous ridge were identified as we continued our approach toward the petrous apex. From the petrous apex, a point $2 \mathrm{~cm}$ posterolateral which we called point A (-Figs. 1a, 2a, 2b, 3b, 3c, and $\mathbf{4 a}$ ) on the petrous ridge was marked (this was our hypothesis from the initial experimental head). Drilling was commenced here to create a 4 to $5 \mathrm{~mm}$ crater, and as we drilled deeper the PA was identified by noting the dura of the auditory-facial fasciculus entering the petrous temporal bone (-Fig. $\mathbf{3 c}$, d). A straight line was then drawn connecting the FO and the FS, and this line extrapolated posteriorly along the middle fossa floor. A point $2 \mathrm{~cm}$ from the FS was marked on this FO-FS line which we called point B ( - Figs. 1b, 2b, 3e, and $\mathbf{4 b}$ ). The drilled crater on the petrous ridge was now connected with this point by another straight line. This line according to our hypothesis marked the direction and path of the IAC, and this was tested in the remaining cadaver heads. In the last (21st) side unlike the previous dissections, we preserved the mandibular (V3) nerve and the greater superficial petrosal nerve (GSPN) and performed our dissection with the constraints of space and neurovascular structures to contend with simulating an intraoperative scenario to evaluate practicality, easy of dissection, and feasibility.

\section{Results}

In our experimental dissection on the first cadaveric head, a middle fossa approach as well as a suboccipital craniotomy were performed to understand the orientation of landmarks and formulate a hypothesis. In this specimen the PA was identified from the posterior approach and once the seventh/ eighth nerves were identified, drilling was started at the PA, and the IAC was skeletonized into the middle fossa as the nerves were traced into the petrous temporal bone. Once the IAC had been drilled open it was examined from the middle fossa approach. In this specimen we found that this direction of IAC if extended further by a line would intersect the straight line connecting the FO and FS at a point $\sim 2 \mathrm{~cm}$ from the FS. Thus, our hypothesis was a $2 \mathrm{~cm} \times 2 \mathrm{~cm}$ method whereby a point $2 \mathrm{~cm}$ from the petrous apex along the petrous ridge (point $\mathrm{A}$ ) if drilled downward would expose the PA; then a point $2 \mathrm{~cm}$ from the FS on the FO-FS line (point $B$ ) if connected to the drilled PA point would give the direction of the IAC and in this manner the IAC can be unroofed from an expanded middle fossa approach. In the 21 sides dissected, the PA was found at a mean distance of $2.38 \mathrm{~cm}$ (range 2.1 to $2.8 \mathrm{~cm}$ ) from the petrous apex on the petrous ridge (point A) and the point where the IAC intersected the FO-FS line was a mean of $2.39 \mathrm{~cm}$ (range 2.1 to $2.8 \mathrm{~cm}$ ) from the FS (point B). The findings are presented in -Table $\mathbf{1}$ and $\mathbf{- F i g s .} \mathbf{1} \mathbf{a}$ to $\mathbf{4 b}$ depict the pictorial results of the study.

The facial and vestibule-cochlear nerves were found to be deeper medially at the porous and then were more superficial as they coursed along laterally in the IAC; this anatomic nuance has been reported previously. ${ }^{17}$

\section{Discussion}

The middle fossa approach is most often used for removal of small intracanalicular acoustic tumors, and preservation of hearing and facial nerve function is possible in most patients with this approach ${ }^{7}$; thus the approach is useful in case of smaller tumors and in those with preserved hearing. Many acoustic tumors if detected early which has been made possible with improvement in imaging would therefore tend to be small and would not have affected hearing significantly. However, there are many pathologies that require an expanded middle fossa approach with exposure of the petrous apex. We propose our method as an alternative to existing IAC identifying methods, in cases where an expanded middle fossa approach is required. This approach is necessary for adequate exposure and treatment of pathology affecting the petrous apex, petroclival region, and the coronal plane 
A
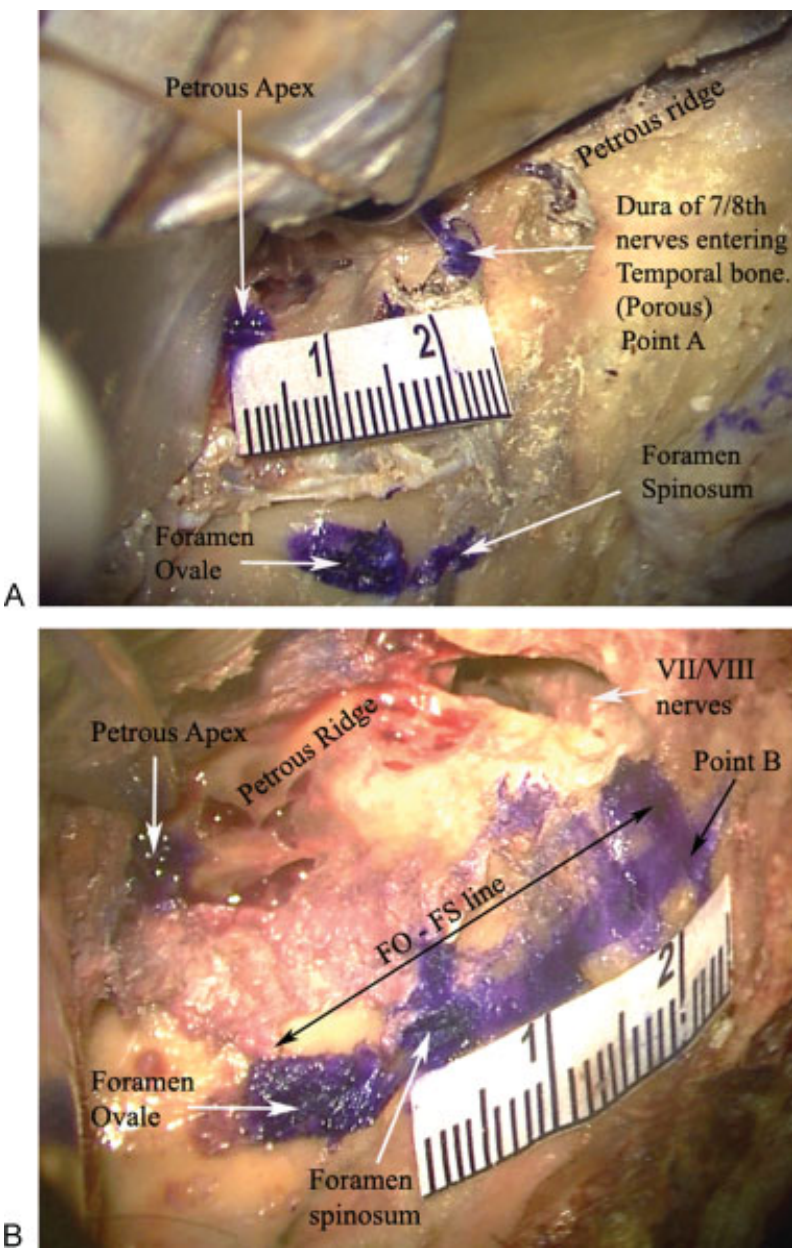

Figure 1 (A) Exposure of the left middle fossa floor showing the bony landmarks. At point A where drilling was commenced the dura of the seventh/eighth nerves entering the temporal bone at the porous acousticus is shown which has been colored blue. The distance from the petrous apex to this point has been measured $(2.4 \mathrm{~cm}$ in this case). (B) Dissection has been completed here with the exposure of the seventh/eighth nerves within the skeletonized IAC. Point B represents where the IAC intersects the foramen ovale-foramen spinosum line (FO-FS line), in this case at $2.4 \mathrm{~cm}$ from the FS on the line. IAC, internal acoustic canal.

between Meckel's cave and the IAC. Pathology such as petroclival meningioma, trigeminal schwannoma with similar sized middle and posterior fossa components, large vestibular schwannomas, extensive chondrosarcoma, or middle cranial fossa skull base malignancies are often quite large at the time of diagnosis; we propose the rule of $2 \mathrm{~s}$ as an alternative method of safely identifying the IAC to maximize facial nerve preservation. These can be effectively removed in their entirety as complete exposure of the IAC can be achieved with the expanded middle fossa approach. With the retrosigmoid approach to expose the IAC both more structures are encountered and smaller operative space is available. Blevins and Jackler ${ }^{14}$ performed computed tomography (CT) scans of temporal bones to estimate the extent of visualization of the IAC in a retrosigmoid approach (radio-anatomical study). They found that only some part of the lateral extent of the IAC could be exposed without compromising the integrity of

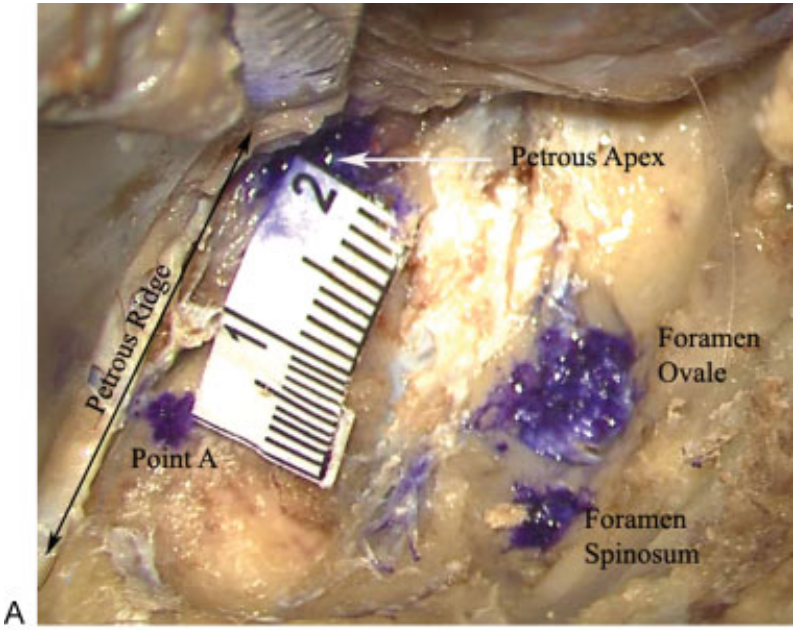

A

the inner ear and lateral one-third $(3 \mathrm{~mm}$ ) of IAC was inaccessible without damaging the labyrinth. One extra centimeter cerebellar retraction was needed to visualize each extra millimeter of the IAC laterally. Tanriover et $\mathrm{al}^{11}$ also applied the subtemporal approach to expose the IAC in a cadaveric study by separating the dura of the middle fossa from the floor in an anterior to posterior fashion. The GSPN nerve was used as a guiding landmark and the angle between the nerve and the IAC was noted to be 61 degrees. This was a modification of the method described by Garcia-Ibanez and Garcia-Ibanez. ${ }^{6}$ The method was useful to expose the cisternal, meatal, labyrinthine, and tympanic parts of the facial nerve and was used in one patient. The authors mention that the drilling commenced medially on the petrous ridge but precisely what landmarks or measurements were used to identify the starting point of the drilling on the petrous ridge was not mentioned; probably the 61 degrees angle between the GSPN and the IAC line was extrapolated toward the petrous ridge to denote the starting point. Also measuring angles precisely intraoperatively is technically difficult to perform. In the method we used, we used a fixed constant 

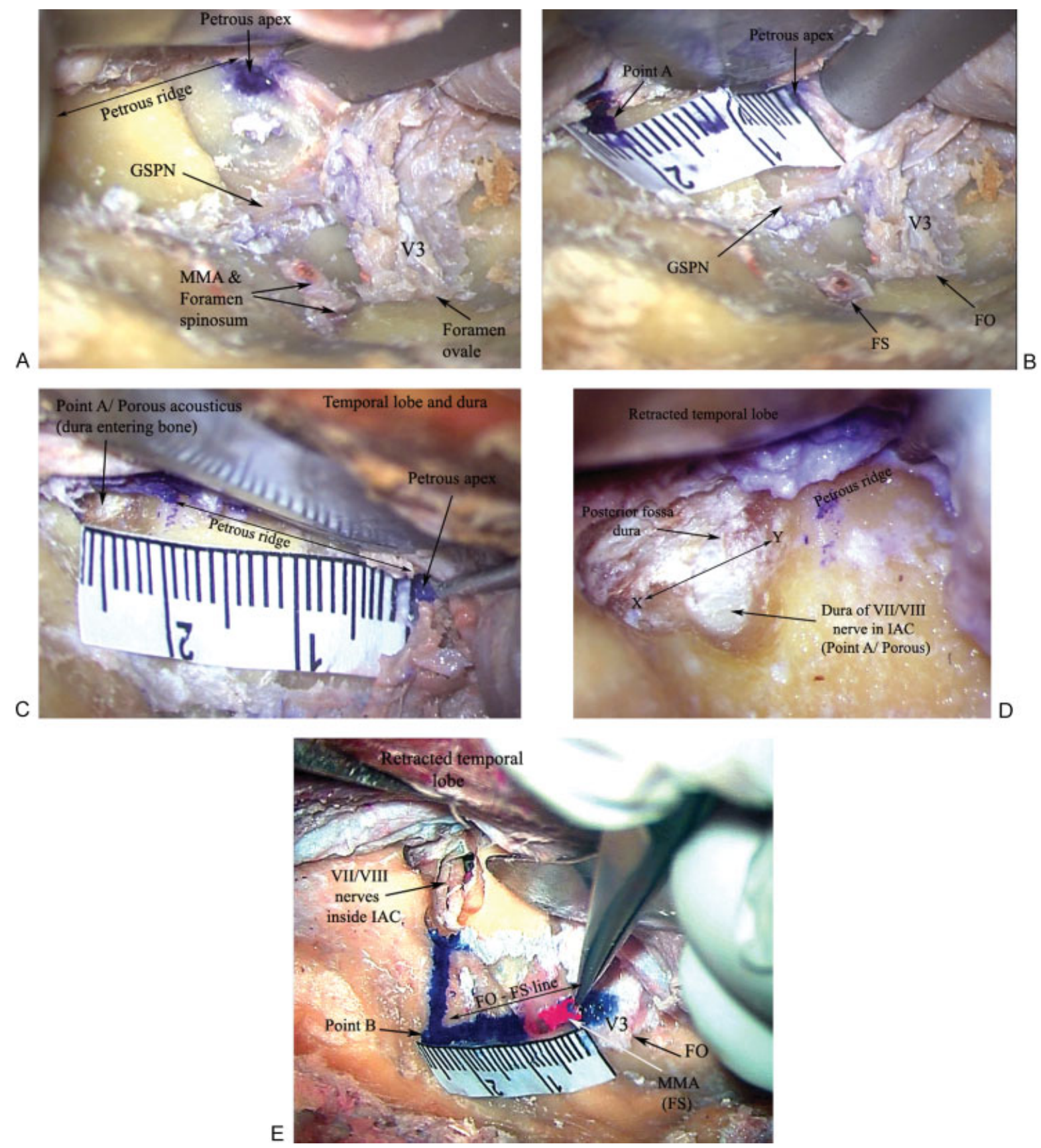

Figure 3 (A) Dissection on the right side in the final cadaver (21st side) where the mandibular (V3) nerve and GSPN have been preserved to render an operative scenario with constraints of space and critical structures. MMA has been sectioned and rest of the middle fossa landmarks are shown. (B) Point A is marked on the petrous ridge $2 \mathrm{~cm}$ from the petrous apex. Mandibular nerve (V3) and FO and FS are shown. (C) After drilling at point A the dura of the seventh/eighth nerves entering the IAC at the porous acousticus is encountered and its distance from the petrous apex is measured ( $2.5 \mathrm{~cm}$ in this case). (D) A close-up image of the drilled open point A showing the posterior fossa dura and the dura of the seventh/eighth nerve entering the IAC. Line X-Y marks where the posterior fossa dura turns inward to enter the IAC covering the vestibule-facial fasciculus. (E) Completed dissection showing the nerves within the skeletonized IAC, all bony landmarks, and point A and point B ( $2.5 \mathrm{~cm}$ from FS in this case). The retracted temporal lobe, V3 nerve, and the sectioned MMA are shown along with FS and FO. FO, foramen ovale; FS, foramen spinosum; GSPN, greater superficial petrosal nerve; IAC, internal acoustic canal; MMA, middle meningeal artery.

landmark, namely, the petrous apex to localize a precise point on the petrous ridge to commence drilling to expose the PA and the dura of the seventh/eighth nerves entering the petrous temporal bone. In our approach of exposing the facial and vestibule-cochlear nerves, when the dura inside the IAC was split open the origins of the nerves from the pontomedullary junction (cisternal part) could be well visualized and so also the succeeding portions of the nerve. With the PA being located in the posterior fossa and the IAC being completely located within the petrous temporal bone, the PA and IAC would thus require identification indirectly using landmarks in the middle fossa as reference points. These landmarks and methods are described using the arcuate eminence (AE), ${ }^{3,18}$ GSPN, superior semicircular canal 


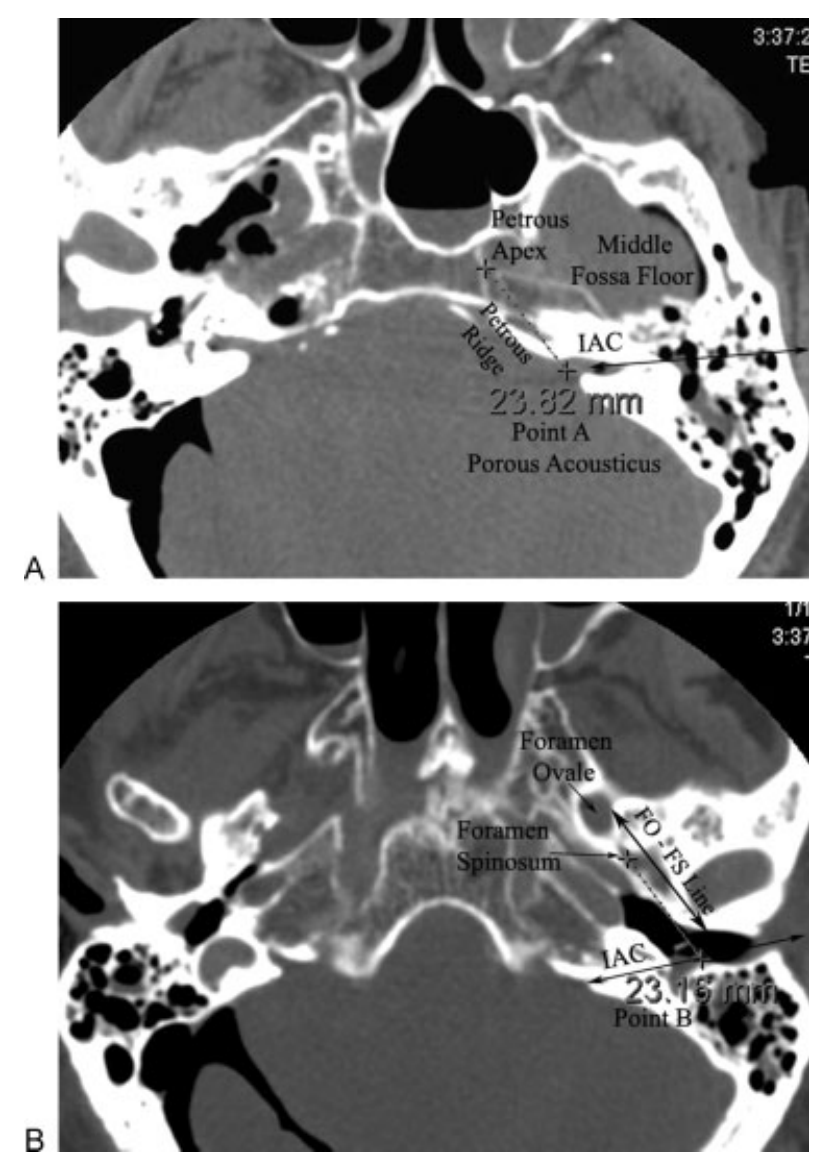

Figure 4 (A) Axial computed tomography scan of one cadaveric head showing the distance of the porous acusticus from petrous apex. (B) A lower axial cut showing distance of point $B$ (where IAC intersects the FO-FS line) from foramen spinosum. FO, foramen ovale; FS, foramen spinosum; IAC, internal acoustic canal.

(SCC), 3,5-8,13,18 external landmarks such as the root of the zygoma and angles formed by the posterior and anterior origin of the root of the zygoma with the FS and PA. ${ }^{2,9}$ While each of these methods provides a reasonable method of identifying the IAC, they are not too precise and are mostly estimations. Furthermore, some methods are technically difficult to apply intraoperatively. In addition, some other controversies exist, for example, the $\mathrm{AE}$ being a protuberance of the SCC is contested and said to be the markings of the occipitotemporal sulcus. Tsunoda et al studied temporal bones and found that the $\mathrm{AE}$ was not seen in $8 \%$ of the specimens ${ }^{17}$ and most of the AEs had no strict positional correspondence to the SCC. Rather the AE was found to correspond to the occipitotemporal sulcus. The authors in their study of more temporal bones found that only $80 \%$ of the specimens actually showed an $\mathrm{AE}$, and these did not exactly correspond to the SCC. ${ }^{19,20}$ Kartush et al ${ }^{18}$ similarly reported that $\sim 85 \%$ of the temporal bones that were studied showed an $\mathrm{AE}$. They also noted that a variability of the AE overlying the SCC existed. They therefore concluded that the AE should not be used as substitute for SSC in locating IAC. Instead the GSPN was used as one of the guiding structures to dissect toward the geniculate ganglion. Further description of localizing the SSC by using the anterior border of geniculate ganglion and
Table 1 Observations in 20 Cadaveric Sides Regarding Location of PA and IAC

\begin{tabular}{|c|c|c|}
\hline Side No. & $\begin{array}{l}\text { PA from Petrous } \\
\text { Apex at Distance } \\
\text { (cm) }\end{array}$ & $\begin{array}{l}\text { IAC Intersection } \\
\text { with FO-FS Line, } \\
\text { Distance from FS } \\
\text { (cm) }\end{array}$ \\
\hline 1 & 2.2 & 2.1 \\
\hline 2 & 2.1 & 2.2 \\
\hline 3 & 2.2 & 2.3 \\
\hline 4 & 2.3 & 2.2 \\
\hline 5 & 2.3 & 2.4 \\
\hline 6 & 2.3 & 2.4 \\
\hline 7 & 2.4 & 2.3 \\
\hline 8 & 2.5 & 2.3 \\
\hline 9 & 2.3 & 2.5 \\
\hline 10 & 2.3 & 2.5 \\
\hline 11 & 2.4 & 2.5 \\
\hline 12 & 2.4 & 2.5 \\
\hline 13 & 2.4 & 2.5 \\
\hline 14 & 2.4 & 2.5 \\
\hline 15 & 2.5 & 2.1 \\
\hline 16 & 2.8 & 2.4 \\
\hline 17 & 2.4 & 2.8 \\
\hline 18 & 2.5 & 2.5 \\
\hline 19 & 2.5 & 2.2 \\
\hline 20 & 2.4 & 2.5 \\
\hline $\begin{array}{l}21 \\
\text { Structures } \\
\text { preserved/ } \\
\text { operative } \\
\text { simulation }\end{array}$ & 2.4 & 2.4 \\
\hline Mean & 2.38 & 2.39 \\
\hline Median & 2.4 & 2.4 \\
\hline
\end{tabular}

FO, foramen ovale; FS, foramen spinosum IAC, internal acoustic canal; $\mathrm{PA}$, porous acusticus.

proceeding in posterior and medial directions were made; however, these can be difficult to reproduce intraoperatively because of being technically cumbersome and complicated. Furthermore, the anterior border of geniculate ganglion might not be a reliable and consistent landmarks as most soft-tissue structures are variable. For this reason we used bony landmarks, and those that are very constant.

The middle cranial fossa approach was popularized by House in the middle part of the 19th century ${ }^{8}$ for exposing the IAC for removal of acoustic neuromas, but the approach had been promulgated earlier by Horsley et al for relief of tic douloureux. ${ }^{19}$ This approach is definitively effective in providing complete exposure of the IAC. The techniques described by House use the GSPN to locate the geniculate ganglion, and thence the facial nerve is followed to expose the rest of the IAC. Garcia-Ibanez and Garcia-Ibanez ${ }^{6}$ first 
described the position of the IAC to be along the line bisecting the angle between the GSPN and the AE. The length of IAC has been reported to be 9.5 to $22 \mathrm{~mm}$ (mean $14.9 \mathrm{~mm}$ ) in one study, ${ }^{4}$ and 8 to $16 \mathrm{~mm}$ (mean $11.8 \mathrm{~mm}$ ) in another temporal bone study. ${ }^{21}$ Driscoll et al recorded the intraoperative measurements of line of sight and angles when adopting a middle fossa approach and studied these angles by projecting them on CT scans of temporal bones. ${ }^{4}$ Of the total length of the IAC floor, a mean $25 \%$ (14 to 34\%) of the floor was found to be not directly visible when approaching through the middle fossa and that tumors extending into the most lateral portion of the IAC were difficult to resect. However, their method of exposing the IAC was in a lateral rather than an anterolateral approach from atop the EAC, thus the line of vision viewed the IAC from on top of it. Our craniotomy extended anterior to the EAC and the anterolateral line of vision allowed visualization of the entire IAC ( - Figs. 1b, 2b, and 3e). Cokkeser et $\mathrm{al}^{3}$ also performed the craniotomy two-third anterior and onethird posterior to the EAC. The GSPN and the AE were used as landmarks, and the line bisecting the angle between them was taken as the location of the IAC. While drilling was started medially, the technique was used in 45 operated cases however the method of identifying the porous via the middle fossa approach was not mentioned. Lee et $\mathrm{al}^{9}$ described a new method of identifying the IAC though the middle fossa approach. Multiple imaginary lines, various landmarks, and a multitude of distances and angles were calculated. Although the IAC was reliably located, the process was complex. It is difficult to replicate intraoperatively the drawing imaginary lines between posterior root of zygoma, FS, FO, and anterior and posterior borders PA, and then to calculate the angles between these various lines. Furthermore through the middle fossa approach, the PA cannot be visualized as it opens into the posterior fossa thus any method through the middle fossa should first address how to localize the PA before identifying path of the IAC. A simple and straight forward method, employing minimum calculations or estimations, and using constant and consistent bony landmarks would be most useful during surgery. We believe our $2 \mathrm{~cm} \times 2 \mathrm{~cm}$ method is simple, easy to reproduce intraoperatively as seen in our dissection in the last side (21st) with preserved neurovascular structures.

Jackler and Gladstone reported on locating the IAC in the middle fossa approach and their technique was somewhat similar to our method of exposing the IAC, ${ }^{22}$ but while we defined a precise point $2 \mathrm{~cm}$ on the petrous ridge from the petrous apex to commence drilling, they however mention commencing drilling near the "estimated" location of the porous and subsequently creating a "deep and wide trough" at the petrous apex extending it posteriorly until the dural covering of the IAC is encountered. We performed drilling at precise points, did not use estimations, and did not need to create a deep and wide trough thereby reducing drilling time, bone loss, and avoiding injury to any nearby neurovascular structures. Here again, while we initially performed drilling open the IAC by following the seventh/eighth nerves, we had formulated a hypothesis that the orientation of the IAC was along a line connecting the point on the petrous ridge $(2 \mathrm{~cm}$ point from petrous apex) to a point on the FO-FS line $(2 \mathrm{~cm}$ from the FS). Our method would be suited for middle fossa lesions that require an extension of the approach, aided by extended corresponding landmarks.

Successful clinical application using AE and GSPN has been reported nonetheless. An extended middle fossa approach was described by Wigand et al $^{13}$ that was employed in 209 patients. The line bisecting the angle between the SCC/AE and the GSPN was used to orient to the direction of the IAC. ${ }^{12,13}$ Complete tumor removal was achieved in all cases with no recurrence in a follow-up period of 10 years. In the extended middle fossa approach, ${ }^{12}$ the petrous pyramid, bone anterior and posterior to the IAC was removed. This approach is suited to expose the cerebellopontine (CP) angle. Our method would be mostly suited for small intracanalicular acoustic neuromas or meningiomas. To expose the $\mathrm{CP}$ angle, part of the sigmoid sinus, ventral pons, 9th, 10 th, and 11 th nerves along with the IAC, Bochenek et $\mathrm{al}^{1}$ described the extended middle fossa approach where additional bone was removed on the petrous pyramid laterally along with sectioning of the tentorium cerebelli. Some of the important previous studies identifying the IAC in the middle fossa approach, the anatomic landmarks used, results and drawbacks, and comparison to our study are mentioned in - Table 2.

\section{Limitations and Technical Difficulties in Our Method}

The dissection toward the petrous apex is challenging as dissection is deep toward the midline of the skull base requiring more retraction of the temporal lobe. Use of a lumbar drain as practiced in most cases of extradural lesions would facilitate in dissection. Our method was tested in cadavers and was technically feasible; however, its applicability remains to be studied in real patients.

We also acknowledge that stereotactic navigation can be yet another adjunct help identify the IAC intraoperatively. However, our study outlines important anatomical relationships that would be reproducible even in the absence of navigation. We offer this as an important learning point, especially for more junior skull base surgeons and neurootologists.

\section{Conclusion}

The expanded middle cranial fossa approach is important to surgically remove large petroclival meningiomas, trigeminal schwannomas, large vestibular schwannomas, extensive lateral clival chondrosarcomas, and middle fossa skull base malignancies. Multiple methods of identification of the IAC through the middle cranial fossa have been described, both in anatomical and clinical series. These methods are mostly based on estimations and imaginary lines/planes and angles which can be difficult to envision in an intraoperative setting. We have described a simple, novel, and reliable method of identification of the IAC in the expanded middle fossa approach using consistent landmarks and precise bony points which can be easily reproduced. Application in real patients 
Table 2 Studies that Determined Location of IAC in Middle Fossa Approaches

\begin{tabular}{|c|c|c|c|c|}
\hline Study & $\begin{array}{l}\text { Approach, } \\
\text { Landmarks Used }\end{array}$ & Study Type & Results & Comments/Drawbacks \\
\hline $\begin{array}{l}\text { Tsunoda et al, } \\
2000^{17}\end{array}$ & $\begin{array}{l}\mathrm{AE} \text { and relationship to } \\
\mathrm{SCC}\end{array}$ & Anatomical & $\begin{array}{l}\text { AE, a trace of occipitotemporal } \\
\text { sulcus, not of SSC; present in 10\% of } \\
\text { specimens; high variability on } \\
\text { petrous bone surface }\end{array}$ & $\begin{array}{l}\mathrm{AE} \text { and SCC are not appropriate } \\
\text { landmarks to identify IAC. }\end{array}$ \\
\hline $\begin{array}{l}\text { Tsunoda, } \\
2001^{20}\end{array}$ & $\begin{array}{l}\mathrm{AE} \text { and relationship to } \\
\mathrm{SCC}\end{array}$ & Anatomical & $\begin{array}{l}\text { SSC-MCF distance varied; AE absent } \\
\text { in } 19 \% \text { of specimens; SSC did not } \\
\text { influence the surface of MCF }\end{array}$ & $\begin{array}{l}\mathrm{AE} \text { and SCC are not appropriate } \\
\text { landmarks to identify IAC. }\end{array}$ \\
\hline $\begin{array}{l}\text { Lee et al, } \\
2006^{9}\end{array}$ & FS, zygomatic arch, PA & Anatomical & $\begin{array}{l}\text { Imaginary line between FS and } \\
\text { posterior root of zygomatic arch } \\
\text { forms } 90 \text { degrees angle with line } \\
\text { between FS and PA }\end{array}$ & $\begin{array}{l}\text { Difficulty in conceptualizing } \\
\text { various imaginary lines and } \\
\text { multiple distances and angles; } \\
\text { variability in distances between } \\
\text { external/internal landmarks and } \\
\text { angles; landmarks lie outside of } \\
\text { microscopic operative field. }\end{array}$ \\
\hline $\begin{array}{l}\text { Cokkeser et al, } \\
2001^{3}\end{array}$ & $\begin{array}{l}\text { AE, GSPN, and } \\
\text { bisection of angle } \\
\text { between the two gives } \\
\text { orientation of IAC }\end{array}$ & Anatomical & $\begin{array}{l}\text { IAC threefold wider at porous than } \\
\text { at fundus }\end{array}$ & $\begin{array}{l}\text { IAC exposure started medially; } \\
\text { method of identification of PA } \\
\text { not mentioned; bisecting angle } \\
\text { an estimation and not precise; } \\
\text { controversy about AE and SCC } \\
\text { relationship. }\end{array}$ \\
\hline $\begin{array}{l}\text { House, } \\
1961^{8}\end{array}$ & $\begin{array}{l}\text { GSPN traced to } \\
\text { geniculate ganglion } \\
\text { and VII nerve then } \\
\text { traced to IAC }\end{array}$ & Surgical & $\begin{array}{l}\text { Established microsurgical } \\
\text { technique to expose IAC in middle } \\
\text { fossa approach }\end{array}$ & $\begin{array}{l}\text { Commencing dissection at } \\
\text { fundus puts contents of } \\
\text { labyrinth at risk of damage. }\end{array}$ \\
\hline $\begin{array}{l}\text { Jackler and } \\
\text { Gladstone, } \\
1995^{22}\end{array}$ & $\begin{array}{l}\mathrm{AE}, \mathrm{GSPN} \text {, and } \mathrm{EAC} \\
\text { used }\end{array}$ & Surgical & $\begin{array}{l}\text { Deep trough created in anterior } \\
\text { petrous apex to identify dura } \\
\text { within IAC }\end{array}$ & $\begin{array}{l}\text { Drilling commenced at } \\
\text { "estimated" location of PA; } \\
\text { "deep trough" created to } \\
\text { identify dura within IAC; } \\
\text { increased operative time, bone } \\
\text { loss, and risk of damage to } \\
\text { neurovascular structures. }\end{array}$ \\
\hline $\begin{array}{l}\text { Kartush et al, } \\
1985^{18}\end{array}$ & $\begin{array}{l}\text { GSPN traced to } \\
\text { geniculate ganglion } \\
\text { and IAC traced }\end{array}$ & Anatomical & $\begin{array}{l}\text { AE not always present and does not } \\
\text { correspond to the SSC, and thus } \\
\text { should not be used as an approach } \\
\text { to identify the IAC }\end{array}$ & $\begin{array}{l}\text { Soft structure variability when } \\
\text { used as landmarks. }\end{array}$ \\
\hline $\begin{array}{l}\text { Garcia-Ibanez and } \\
\text { Garcia- Ibanez, } \\
1980^{6}\end{array}$ & AE, GSPN & Surgical & $\begin{array}{l}\text { IAC along line bisecting angle } \\
\text { between AE and GSPN }\end{array}$ & $\begin{array}{l}\text { AE can be obscure/absent in } \\
\text { some patients; bisecting angle } \\
\text { estimation although used } \\
\text { successfully in patients. }\end{array}$ \\
\hline $\begin{array}{l}\text { Catalano et al, } \\
1993^{2}\end{array}$ & $\begin{array}{l}\text { Lateral cortex of the } \\
\text { temporal squamosa at } \\
\text { the zygomatic root, } \\
\text { head of the malleus }\end{array}$ & $\begin{array}{l}\text { Anatomical and } \\
\text { surgical }\end{array}$ & $\begin{array}{l}\text { Head of the malleus consistently } \\
\text { located } 18 \mathrm{~mm} \text { from outer cortex } \\
\text { (of reference plane); medial exten- } \\
\text { sion of this line through the malleus } \\
\text { head bisects the IAC }\end{array}$ & $\begin{array}{l}\text { Use of external landmarks } \\
\text { outside surgical field; imaginary } \\
\text { lines and angles used difficult to } \\
\text { perform and conceptualize } \\
\text { intraoperatively although used } \\
\text { in } 12 \text { patients. }\end{array}$ \\
\hline $\begin{array}{l}\text { Tanriover et al, } \\
2009^{11}\end{array}$ & GSPN & $\begin{array}{l}\text { Anatomical and } \\
\text { surgical }\end{array}$ & $\begin{array}{l}\text { IAC along a line } 61 \text { degrees from } \\
\text { the GSPN. Drilling commenced on } \\
\text { petrous ridge; all parts of seventh } \\
\text { nerve exposed }\end{array}$ & $\begin{array}{l}\text { Imaginary and estimated angle; } \\
\text { again difficulty of imagining an } \\
\text { angle intraoperatively although } \\
\text { used by authors in one patient; } \\
\text { method of identification of PA } \\
\text { not mentioned }\end{array}$ \\
\hline $\begin{array}{l}\text { Current study, } \\
2009\end{array}$ & FO, FS, petrous apex & Anatomical & $\begin{array}{l}\text { PA at } 2.38 \mathrm{~cm} \text { from petrous apex; } \\
\text { IAC intersects FO-FS line at } \\
2.39 \mathrm{~cm} \text { from FS on the FO-FS line }\end{array}$ & $\begin{array}{l}\text { Consistent, reliable landmarks; } \\
\text { precise points used; deep } \\
\text { dissection toward petrous apex } \\
\text { encountering important } \\
\text { structures and more brain } \\
\text { retraction }\end{array}$ \\
\hline
\end{tabular}

AE, arcuate eminence; EAC, external auditory canal; FO, foramen ovale; FS, foramen spinosum; GSPN, greater superficial petrosal nerve; IAC, internal acoustic canal; MCF, middle cranial fossa; PA, porous acusticus; SCC, superior semicircular canal. 
remains to be studied, but based on the results of our dissection this method can potentially become a universally accepted method of exposure of the IAC in the expanded middle fossa approach.

\section{References}

1 Bochenek Z, Kukwa A. An extended approach through the middle cranial fossa to the internal auditory meatus and the cerebellopontine angle. Acta Otolaryngol 1975;80(5-6):410-414

2 Catalano PJ, Eden AR. An external reference to identify the internal auditory canal in middle fossa surgery. Otolaryngol Head Neck Surg 1993;108(2):111-116

3 Cokkeser Y, Aristegui M, Naguib MB, Saleh E, Taibah AK, Sanna M. Identification of internal acoustic canal in the middle cranial fossa approach: a safe technique. Otolaryngol Head Neck Surg 2001; 124(1):94-98

4 Driscoll CL, Jackler RK, Pitts LH, Banthia V. Is the entire fundus of the internal auditory canal visible during the middle fossa approach for acoustic neuroma? Am J Otol 2000;21(3):382-388

5 Fisch U. Transtemporal surgery of the internal auditory canal. Report of 92 cases, technique, indications and results. Adv Otorhinolaryngol 1970;17:203-240

6 Garcia-Ibanez E, Garcia-Ibanez JL. Middle fossa vestibular neurectomy: a report of 373 cases. Otolaryngol Head Neck Surg 1980; 88(4):486-490

7 House WF, Shelton C. Middle fossa approach for acoustic tumor removal. Otolaryngol Clin North Am 1992;25(2):347-359

8 House WF. Surgical exposure of the internal auditory canal and its contents through the middle, cranial fossa. Laryngoscope 1961; 71:1363-1385

9 Lee HK, Kim IS, Lee WS. New method of identifying the internal auditory canal as seen from the middle cranial fossa approach. Ann Otol Rhinol Laryngol 2006;115(6):457-460

10 Parisier SC. The middle cranial fossa approach to the internal auditory canal-an anatomical study stressing critical distances between surgical landmarks. Laryngoscope 1977;87(4 Pt 2, Suppl 4):1-20
11 Tanriover N, Sanus GZ, Ulu MO, et al. Middle fossa approach: microsurgical anatomy and surgical technique from the neurosurgical perspective. Surg Neurol 2009;71(5):586-596, discussion 596

12 Wigand ME, Aurbach G, Haid CT, Berg M, Goertzen W. Topographical anatomy of the internal auditory canal. Implications for functional surgery in the cerebello-pontine angle. Acta Otolaryngol 1991;111(2):269-272

13 Wigand ME, Haid T, Berg M, Schuster B, Goertzen W. Extended middle cranial fossa approach for acoustic neuroma surgery. Skull Base Surg 1991;1(3):183-187

14 Blevins NH, Jackler RK. Exposure of the lateral extremity of the internal auditory canal through the retrosigmoid approach: a radioanatomic study. Otolaryngol Head Neck Surg 1994;111(1): 81-90

15 Molony TB, Kwartler JA, House WF, Hitselberger WE. Extended middle fossa and retrolabyrinthine approaches in acoustic neuroma surgery: case reports. Am J Otol 1992;13(4):360-363

16 Kawase T, Shiobara R. Extended middle cranial fossa approaches to the clivus and acoustic meatus. In: Torrens M, Al-Mefty O, Kobayashi S, eds. Operative Skull Base Surgery. New York: Churchill Livingstone; 1997;263-278

17 Tsunoda A, Kimura Y, Sumi T, Komatsuzaki A, Sato T. The arcuate eminence is not a protrusion of the superior semi-circular canal but a trace of sulcus on the temporal lobe. J Laryngol Otol 2000; 114(5):339-344

18 Kartush JM, Kemink JL, Graham MD. The arcuate eminence. Topographic orientation in middle cranial fossa surgery. Ann Otol Rhinol Laryngol 1985;94(1 Pt 1):25-28

19 Tsunoda A. Arcuate eminence in Caucasian populations. J Laryngol Otol 2001;115(1):9-13

20 Horsley V. The various surgical procedures devised for the relief of trigeminal neuralgia (tic douloureux). BMJ 1891;2(1613): 1139-1143

21 Papangelou L. Study of the human internal auditory canal. Laryngoscope 1972;82(4):617-624

22 Jackler RK, Gladstone HB. Locating the internal auditory canal during the middle fossa approach: an alternative technique. Skull Base Surg 1995;5(2):63-67 